\title{
ASESMEN EUTROFIKASI PERAIRAN PESISIR MENGGUNAKAN METODE INDEKS TROFIK (TRIX)
}

\author{
Oleh \\ Hanif Budi Prayitno ${ }^{1)}$
}

\begin{abstract}
EUTROPHICATION ASSESSMENT METHOD FOR COASTAL WATER USING TROPHIC INDEX (TRIX). Eutrophication, a process in which water bodies experience excessive growth of aquatic plants due to accumulation of land-originated nutrients especially phosphorus and nitrogen, has become a worldwide coastal environmental problem. Its negative impacts have been well known including oxygen depletion, harmful algal blooms, biodiversity reduction and ecosystem degradation. Unfortunately, the occurrence of those impacts is often not well anticipated as the instruments for assessing the quality of coastal and marine environment are weak and hardly available. Therefore, there has been a growing concern in developing appropriate methods for assessing coastal and marine eutrophication. One of the most widely used methods is trophic index (TRIX) due to its good efficacy. However, it is still questionable whether TRIX is a universal index of eutrophication or the scaling of TRIX should be region specific.
\end{abstract}

\section{PENDAHULUAN}

Istilah eutrofikasi berasal dari bahasa

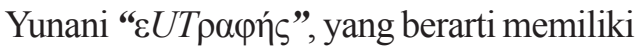
banyak makanan untuk dimakan (Liddel \& Scott dalam Karydis, 2009). Istilah ini digunakan untuk menggambarkan ketersediaan nutrisi atau zat hara di perairan, yang dibutuhkan untuk pertumbuhan alga dan tumbuhan air lainnya berikut tingkat produktivitas perairan tersebut. Suatu perairan dapat dikelompokkan menjadi 3 kelas berdasarkan kandungan zat hara dan tingkat produktivitasnya, yaitu oligotrofi, mesotrofi dan eutrofi (Karydis, 2009). Namun, ada juga studi yang mengelompokkan suatu perairan menjadi 4 kelas, dengan menambahkan 1 kelas lagi yaitu hipertrofi (Karbassi et al., 2016; Lapointe et al., 1994).

Suatu perairan termasuk ke dalam kelas oligotrofi apabila kandungan zat hara dan tingkat produktivitasnya rendah. Kelas eutrofi diperuntukkan bagi perairan yang memiliki kandungan zat hara dan tingkat produktivitas yang tinggi. Adapun istilah mesotrofi dan hipertrofi berturut-turut digunakan untuk menggambarkan perairan dengan kandungan zat hara dan produktivitas yang sedang dan sangat tinggi. Keempat istilah tersebut pada awalnya digunakan oleh para ahli limnologi untuk menggambar-

$\overline{{ }^{1)} \text { Pusat Penelitian Oseanografi LIPI }}$ 
kan kondisi zat hara dan produktivitas perairan darat. Namun, seiring dengan meningkatnya permasalahan lingkungan di perairan pesisir yang ditimbulkan oleh pengayaan zat hara antropogenik, istilah-istilah tersebut menjadi istilah yang umum dijumpai pada literatur-literatur ilmu kelautan (Vollenweider et al., 1998).

\section{DEFINISI EUTROFIKASI}

Meskipun saat ini eutrofikasi merupakan istilah yang sudah umum dipakai untuk menggambarkan hubungan antara konsentrasi zat hara dan peningkatan biomassa fitoplankton, namun beberapa penulis dan ahli berusaha untuk memberikan definisi yang tepat untuk istilah tersebut. Menurut Vollenweider (1992), eutrofikasi adalah proses pengayaan perairan (baik air tawar maupun air laut) dengan zat hara terutama nitrogen dan fosfor, yang merangsang produksi primer perairan. Eutrofikasi mengakibatkan proses lanjutan berupa pertumbuhan alga yang pesat, kemudian munculnya buih alga dan meningkatnya pertumbuhan alga bentik berupa makrofita tenggelam dan makrofita berdaun terapung. Adapun Gray (1992) mendefinisikan eutrofikasi sebagai suatu peristiwa yang terjadi apabila zat hara ditambahkan ke dalam badan air dengan syarat zat hara tersebut tidak bersifat racun dan tesedia cukup cahaya untuk peningkatan pertumbuhan organisme autotrof dan heterotrof.

Definisi eutrofikasi dengan mengkombinasikan antara pengayaan zat hara, pertumbuhan alga dan gangguan ekosistem dikemukankan oleh Ferreira et al. (2010). Dalam laporannya, eutrofikasi didefinisikan sebagai suatu proses yang dikendalikan oleh pengayaan zat hara di perairan, terutama oleh senyawa-senyawa nitrogen dan atau fosfor yang menyebabkan peningkatan pertumbuhan produktivitas primer dan biomassa alga, perubahan keseimbangan organisme dan degradasi kualitas air. Definisi yang lebih sederhana dikemukakan oleh Nixon (1995) yang menyatakan bahwa eutrofikasi adalah kenaikan laju suplai bahan organik ke suatu ekosistem. Dari seluruh definisi tersebut perbedaannya hanyalah pada penekanan dampak yang timbul. Pada intinya semua definisi menyepakati bahwa eutrofikasi melibatkan peningkatan material alga. Selain itu, eutrofikasi hanya dianggap sebagai gangguan dan bukan sebagai suatu bentuk pencemaran.
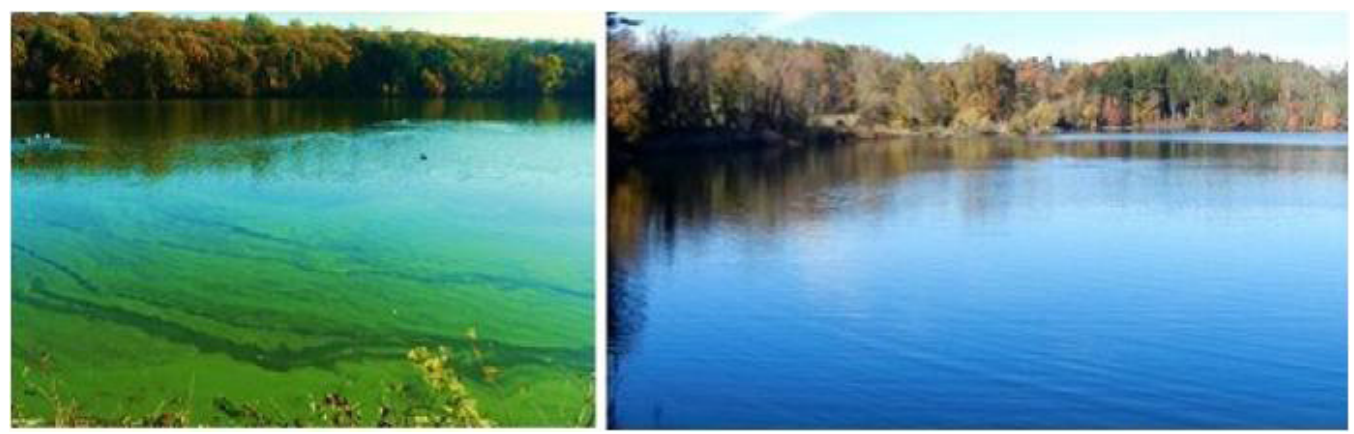

Gambar 1. Perbandingan perairan yang normal (kanan) dan yang tertutupi oleh alga atau mengalami eutrofikasi (kiri) (www.theeutrophysolution.com/enzymatic-digestion/). 


\section{DAMPAK EUTROFIKASI}

Meskipun tidak dianggap sebagai suatu bentuk pencemaran, dampak negatif yang ditimbulkan oleh eutrofikasi cukup besar. Saat ini eutrofikasi telah menjadi permasalahan lingkungan yang serius, terutama di perairan yang semi tertutup, dan teluk yang sedikit mengalami pertukaran massa air (Gray, 1992). Bahkan Fiori et al. (2016) menyebutnya sebagai salah satu ancaman terbesar bagi kesehatan ekosistem laut. Dampak negatif dari eutrofikasi semua diawali dengan pertumbuhan fitoplankton, mikroalga dan makroalga yang pesat. Pada tingkatan tertentu, pertumbuhan alga yang tinggi menyebabkan jumlah ikan melimpah (Snickars et al., 2015). Namun apabila pertumbuhan alga di suatu perairan terlalu berlebih, maka yang terjadi adalah munculnya berbagai macam permasalahan.

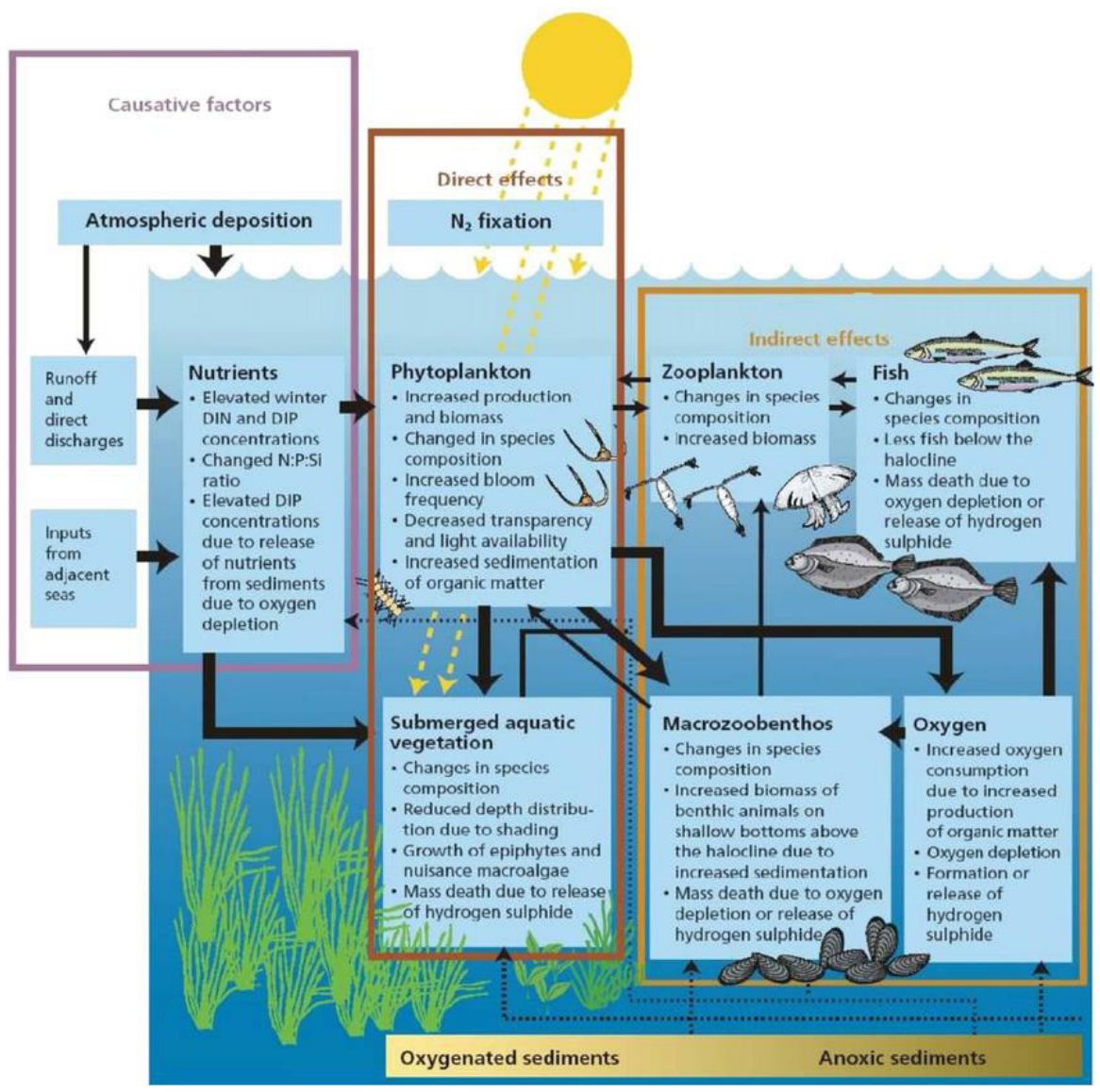

Gambar 2. Model konsep eutrofikasi (Ferreira et al., 2011)

Beberapa dampak negatif yang diakibatkan oleh eutrofikasi diantaranya adalah penurunan konsentrasi oksigen di dasar perairan, penurunan biodiversitas, ledakan populasi alga berbahaya, dan degradasi ekosistem (Boesch, 2002). 
1. Penurunan konsentrasi oksigen. Jika vegetasi darat dijadikan sebagai pembanding, mungkin ada kalangan yang bertanya bagaimana caranya alga yang tumbuh dan berkembang pesat dapat menyebabkan penurunan konsentrasi oksigen. Dalam pemahamannya, alga yang merupakan tumbuhan air pastilah menghasilkan oksigen juga seperti tumbuhan darat. Yang belum disadari oleh mereka yang memiliki pemikiran demikian adalah bahwasanya apabila alga tersebut mati, maka alga tersebut akan mengendap ke dasar perairan. Di dasar perairan, alga yang sudah mati tersebut akan terurai menjadi material anorganik dan proses penguraian tersebut membutuhkan oksigen. Semakin banyak alga yang mati dan mengendap, semakin banyak pula oksigen yang dibutuhkan untuk mengurainya, sehingga, konsentrasi oksigen khususnya di dasar perairan menjadi menurun. Wilayah perairan yang konsentasi oksigennya kurang dari $2 \mathrm{mg} / \mathrm{l}$ dikatakan sedang mengalami kondisi hipoksia. Di Teluk Meksiko, kondisi hipoksia sering terjadi pada musim panas. Areanya semakin bertambah luas sejak tahun 1950an, dan telah menyebabkan kematian bagi banyak hewan laut, sehingga area tersebut dikenal dengan istilah "zona kematian" (Dodds, 2006).

\section{Penurunan biodiversitas}

Pertumbuhan alga yang pesat di kolom air menyebabkan kecerahan air menurun. Sebagai akibatnya, penetrasi cahaya ke dasar perairan menjadi terhalang, sehingga ketersediaan cahaya bagi tumbuhan air yang hidup di dasar perairan menjadi berkurang. Keterbatasan cahaya tentunya menyebabkan tumbuhan yang hidup di dasar perairan sulit untuk tumbuh dan berkembang dan pada akhirnya akan mati. Kematian tumbuhan di dasar perairan ini juga disebabkan oleh gas hidrogen sulfida $\left(\mathrm{H}_{2} \mathrm{~S}\right)$ yang dihasilkan saat penguraian alga yang mati dan mengendap di dasar perairan. Selain menyebabkan kematian tumbuhan dasar perairan, eutrofikasi juga menyebabkan kematian organisme bentik lainnya melalui sedimentasi, penurunan konsentrasi oksigen dan gas $\mathrm{H}_{2} \mathrm{~S}$. Tidak dapat dipungkiri bahwasanya hanya organisme yang mampu beradaptasi dan juga memiliki ketahanan hidup tinggi saja yang dapat bertahan dari tekanan eutrofikasi. Oleh karena itu, eutrofikasi dapat mengakibatkan penurunan biodiversitas perairan.

3. Ledakan populasi alga berbahaya Ada dua kategori alga berbahaya. Pertama, alga dikatakan berbahaya karena spesies alga tersebut menghasilkan toksin atau racun. Kedua, alga dikatakan berbahaya karena biomassanya yang tinggi. Beberapa tipe alga seperti Karenina, Alexandrium, Dinophysis dan Pseudonitzschia menghasilkan toksin (Ferreira et al., 2011) yang dapat meyebabkan penyakit dan kematian bagi beberapa biota laut, seperti lobster, ikan, kerang dan mamalia laut. Toksin tersebut tidak saja berbahaya bagi biota laut, 
namun juga dapat membahayakan manusia yang mengkonsumsi biota laut yang terpapar toksin alga. Selain melalui konsumsi produk laut, toksin alga juga berbahaya bagi manusia apabila manusia minum atau mengalami kontak langsung dengan air yang terkontaminasi toksin alga.

Biomassa alga yang tinggi juga berbahaya. Selain dapat menyebabkan kondisi hipoksia dan menghambat penetrasi cahaya bagi tumbuhan dan hewan bentik, biomassa alga yang tinggi menyebabkan air menjadi keruh, sehingga mengurangi kemampuan biota air untuk mencari makanannya. Selain itu, biomassa alga yang tinggi dapat menyumbat insang ikan. Biomassa alga yang tinggi di perairan sering dikenal dengan istilah "red tides" atau "pasang merah" meskipun biomassa alga yang tinggi tidak selalu menyebabkan warna merah pada badan air. Terkadang warna yang ditimbulkan adalah kuning, jingga, coklat, hijau, putih atau merah muda, tergantung pada tipe fitoplankton yang menyebabkan apakah dinoflagellata, diatom atau alga hijau-biru (Ibrahim, 2007).

4. Degradasi ekosistem

Degradasi ekosistem merupakan bentuk penurunan kondisi kesehatan suatu ekosistem. Ekosistem yang sehat adalah ekosistem yang berfungsi dengan baik dan mampu bertahan, atau pulih dari gangguan (Costanza, 1992). Eutrofikasi tidak saja menyebabkan gangguan pada kondisi abiotik suatu ekosistem, melainkan juga terhadap komunitas biotiknya. Penurunan konsentrasi oksigen, penurunan kecerahan air, dan sedimentasi adalah beberapa indikator degradasi ekosistem dari sisi kondisi abiotiknya. Adapun dari sisi komunitas biotik, indikator degradasi ekosistem dapat berupa penurunan biodiversitas, perubahan struktur komunitas dan juga adanya pergeseran dominasi spesies. Perubahan-perubahan tersebut menyebabkan suatu ekosistem tidak dapat berfungsi dengan baik. Sebagai contoh, eutrofikasi pada ekosistem lamun, akan menyebabkan lamun tidak dapat tumbuh dengan baik bahkan mengalami kematian. Akibatnya ketersediaan pakan untuk kura-kura hijau maupun dugong menjadi berkurang, sehingga populasi kedua biota tersebut menurun. Selain itu, eutrofikasi pada ekosistem lamun menyebabkan hilangnya tempat perlindungan, dan juga tempat bertelur bagi ikan-ikan yang habitatnya di ekosistem lamun.

\section{METODE ASESMEN EUTROFIKASI}

Berdasarkan uraian dampak negatif eutrofikasi yang dijelaskan sebelumnya, peristiwa eutrofikasi dapat dikenali dari gejala primer dan sekunder yang ada. Gejala primer eutrofikasi meliputi respon biologi berupa peningkatan produktivitas primer dalam bentuk peningkatan konsentrasi klorofil-a dan kelimpahan makroalga. Adapun gejala sekunder meliputi 
penurunan konsentrasi oksigen, kehadiran alga pengganggu dan alga beracun, serta hilangnya tumbuhan air seperti lamun. Peristiwa eutrofikasi seringkali terlambat untuk disadari dan diantisipasi. Oleh karena itu, ketersediaan metode untuk memonitor kondisi perairan dan menilai tingkat eutrofikasi sangat penting dalam manajemen perairan pesisir sebagai upaya mencegah degradasi lingkungan akibat eutrofikasi.

Sebagian besar metode asesmen eutrofikasi mengintegrasikan antara indikator biologi dengan indikator fisikokimia untuk menghasilkan informasi dengan tingkat kepercayaan yang tinggi. Hal ini diperlukan, karena informasi tersebut nantinya akan digunakan dalam pengambilan keputusan oleh pihak manajemen kawasan pesisir. Terdapat beberapa macam metode untuk asesmen eutrofikasi perairan pesisir, seperti terangkum dalam Tabel 1. Beberapa di antara metode tersebut hanya menggunakan parameter kolom air tertentu, seperti klorofil-a, oksigen terlarut dan zat hara. Namun demikian, ada juga metode yang meggunakan parameter kolom air tambahan dan parameter lainnya, seperti kecerahan air, kejadiaan ledakan populasi alga berbahaya (HAB), kelimpahan makroalga dan perubahan distribusi tumbuhan bawah air seperti lamun.

Tabel 1. Metode asesmen eutrofikasi perairan pesisir dan indikator yang digunakan (Ferreira et al., 2011).

\begin{tabular}{|l|l|l|}
\hline \multicolumn{1}{|c|}{ Metode } & \multicolumn{1}{|c|}{ Indikator biologi } & \multicolumn{1}{c|}{ Indikator fisiko-kimia } \\
\hline Trophic Index (TRIX) & Klorofil-a & $\begin{array}{l}\text { DO (oksigen terlarut), } \\
\mathrm{DIN}\left(\mathrm{NO}_{2}+\mathrm{NO}_{3}+\mathrm{NH}_{4}\right), \\
\mathrm{TP}(\text { fosfor total) }\end{array}$ \\
\hline $\begin{array}{l}\text { US Environmental Protection Agen- } \\
\text { cy National Coastal Assessment } \\
\text { (EPA NCA) water quality index }\end{array}$ & Klorofil-a & Kecerahan air, DO, DIN, DIP (PO $)$ \\
\hline $\begin{array}{l}\text { Assessment of Estuarine Trophic } \\
\text { Status (ASSETS) }\end{array}$ & $\begin{array}{l}\text { Klorofil-a, makroalga, lamun, HAB (le- } \\
\text { dakan populasi alga berbahaya) }\end{array}$ & DO \\
\hline $\begin{array}{l}\text { Transitional Water Quality Index } \\
\text { (TWQI) }\end{array}$ & Klorofil-a, makroalga, lamun \\
\hline $\begin{array}{l}\text { Oslo-Paris Convention for the Pro- } \\
\text { tection of the Northeast Atlantic } \\
\text { Comprehensive Procedure (OSPAR } \\
\text { COMPP) }\end{array}$ & $\begin{array}{l}\text { Klorofil-a, makroalga, lamun, } \\
\text { fitoplankton spesies indicator }\end{array}$ & $\begin{array}{l}\text { DO, TP, TN (nitrogen total), DIN, } \\
\text { DIP }\end{array}$ \\
\hline $\begin{array}{l}\text { Helsinki Commission Eutrophication } \\
\text { Assessment Tool (HEAT) }\end{array}$ & $\begin{array}{l}\text { Klorofil-a, produktivitas primer, lamun, } \\
\text { invertebrata bentik, HAB, makroalga }\end{array}$ & DIN, DIP, TN, TP, DO, Kecerahan air \\
\hline $\begin{array}{l}\text { Water Framework Directive (WFD) } \\
\text { Fitoplankton, klorofil-a, makroalga, in- } \\
\text { vertebrata bentik, lamun }\end{array}$ & DO, TP, TN, DIN, DIP, Kecerahan air \\
\hline Statistical Trophic Index (STI) & DIN, DIP \\
\hline
\end{tabular}

\section{INDEKS TROFIK (TRIX)}

Salah satu metode asesmen eutrofikasi perairan pesisir yang banyak digunakan adalah indeks trofik (TRIX), yang diperkenalkan oleh Vollenweider et al. (1998). Indeks ini banyak digunakan karena dianggap lebih efektif dibanding- 
kan dengan metode asesmen eutrofikasi lainnya, dan juga karena mencakup rentang kondisi trofik yang luas mulai dari oligotrofi hingga eutrofi. Bahkan, TRIX telah diadopsi oleh aturan hukum di Italia untuk menggambarkan kondisi trofik perairan pesisirnya (Fiori et al., 2016). TRIX pertama kali digunakan untuk mengkarakterisasi kondisi trofik perairan Laut Adriatik di bagian barat laut, tepatnya di sepanjang pesisir wilayah Emilia-Romagna, sebuah wilayah administratif di timur laut Negara Italia.

Indeks TRIX memiliki skala dari 0 hingga 10 untuk membedakan kondisi trofik perairan. Nilai TRIX berikut karakteristik perairan yang diwakilinya ditampilkan pada Tabel 2. Indeks TRIX diperoleh dari perhitungan logaritmik 4 variabel yang berkaitan langsung dengan produktivitas perairan yaitu klorofil-a, oksigen terlarut, nitrogen anorganik terlarut dan fosfor total sesuai persamaan 1 .

TRIX $=(\log [$ Ch $\times$ aD\%O $\times$ DIN $\times$ TP $]-$ $[-1.5]) / 1.2$

(1)

Dengan,

$\mathrm{Ch}=$ Klorofil-a $\left(\mathrm{mg} / \mathrm{m}^{3}\right)$

$\mathrm{aD} \% \mathrm{O}=$ Nilai mutlak deviasi konsentrasi oksigen (\%) terhadap konsentrasi jenuhnya $\left(\mathrm{aD} \% \mathrm{O}=\left|100-\% \mathrm{O}_{2}\right|\right)$

$\mathrm{mN} \quad=$ Nitrogen anorganik terlarut $\left(\mathrm{N}-\mathrm{NO}_{3}+\mathrm{N}-\mathrm{NO}_{2}+\mathrm{N}-\mathrm{NH}_{3}\right)$ $\left(\mathrm{mg} / \mathrm{m}^{3}\right)$

$\mathrm{TP}=$ Fosfor total $\left(\mathrm{mg} / \mathrm{m}^{3}\right)$

Tabel 2. Karakteristik perairan berdasarkan indeks TRIX.

\begin{tabular}{|c|c|c|c|}
\hline Nilai TRIX & Kondisi trofik $^{\text {a) }}$ & Tingkat eutrofikasi ${ }^{\text {b) }}$ & Kondisi perairan $^{\mathrm{c}}$ \\
\hline $0<$ TRIX $<4$ & Oligotrofi & Rendah & $\begin{array}{l}\text { - Produktivitas perairan rendah } \\
\text { - Kecerahan air tinggi } \\
\text { - Ketiadaan anomali warna air } \\
\text { - Konsentrasi oksigen di dasar perairan jenuh. }\end{array}$ \\
\hline $4<$ TRIX $<5$ & Mesotrofi & Sedang & $\begin{array}{l}\text { - Produktivitas perairan sedang } \\
\text { - Air terkadang keruh } \\
\text { - Terkadang muncul anomali warna air } \\
\text { - Terkadang timbul kejadian hipoksia di dasar perairan. }\end{array}$ \\
\hline $5<$ TRIX $<6$ & Eutrofi & Tinggi & $\begin{array}{l}\text { - Produktivitas perairan tinggi } \\
\text { - Kecerahan air rendah } \\
\text { - Sering muncul anomali warna air } \\
\text { - Perairan mengalami hipoksia } \\
\text { - Terkadang timbul kejadian anoksia di dasar perairan } \\
\text { - Organisme bentik mengalami tekanan }\end{array}$ \\
\hline $6<$ TRIX $<10$ & Hipertrofi & Sangat tinggi & $\begin{array}{l}\text { - Produktivitas perairan sangat tinggi } \\
\text { - Kekeruhan air sangat tinggi } \\
\text { - Anomali warna air semakin meluas dan berkelanjutan } \\
\text { - Kejadian hipoksia maupun anoksia semakin meluas } \\
\text { dan berkelanjutan } \\
\text { - Laju kematian organisme bentik tinggi } \\
\text { - Terjadi perubahan komunitas bentik dan penurunan } \\
\text { biodiversitas yang tinggi. }\end{array}$ \\
\hline
\end{tabular}

Sumber: ${ }^{\text {a) }}$ Moncheva et al.(2002), b) Karbassi et al. (2016), ${ }^{\text {c }}$ Fiori et al. (2016) 
Meskipun variabel zat hara yang dianjurkan dalam penghitungan TRIX (persamaan 1) adalah nitrogen anorganik terlarut dan fosfor total (Giovanardi \& Vollenweider, 2004), tetapi persamaan tersebut sangat fleksibel terhadap modifikasi (Vollenweider et al., 1998). Sebagai contoh, nitrogen anorganik terlarut (DIN) dapat diganti dengan nitrogen total (TN), dan fosfor total (TP) dapat diganti dengan fosfor anorganik terlarut (DIP). Dengan demikian, TRIX dapat dihitung dengan menggunakan berbagai kombinasi antara DIN, TN, DIP dan TP. Namun demikian, untuk membedakan antara TRIX hasil penghitungan menggunakan satu kombinasi tertentu dengan kombinasi lainnya sebaiknya digunakan penulisan simbol yang jelas seperti TRIX(DIN,DIP), TRIX(DIN,TP), TRIX(TN,DIP) dan TRIX(TN,TP). Tabel 3 menunjukkan contoh perhitungan TRIX.

Tabel 3. Contoh perhitungan TRIX.

\begin{tabular}{|c|c|c|c|c|c|c|c|}
\hline & $\begin{array}{c}\mathrm{Ch} \\
\mathrm{mg} / \mathrm{m}^{3}\end{array}$ & $\begin{array}{l}\mathrm{DO} \\
(\%)\end{array}$ & $\begin{array}{c}\mathrm{aD} \% \mathrm{O} \\
(|100-\mathrm{DO}|)\end{array}$ & $\begin{array}{c}\mathrm{TN} \\
\mathrm{mg} / \mathrm{m}^{3}\end{array}$ & $\begin{array}{c}\mathrm{TP} \\
\mathrm{mg} / \mathrm{m}^{3}\end{array}$ & $\begin{array}{c}\mathrm{DIN} \\
\mathrm{mg} / \mathrm{m}^{3}\end{array}$ & $\begin{array}{c}\text { DIP } \\
\mathrm{mg} / \mathrm{m}^{3}\end{array}$ \\
\hline Data analitik & 22,3 & 184 & 84 & 728 & 14 & 343 & 5 \\
\hline & \multicolumn{3}{|c|}{ Skor trofik } & \multicolumn{4}{|c|}{ Indeks trofik } \\
\hline TRIX (TN,TP) & \multicolumn{3}{|c|}{$\log (\mathrm{Ch} * \mathrm{aD} \% \mathrm{O} * \mathrm{TN} * \mathrm{TP})=7,28$} & & \multicolumn{3}{|c|}{$(7,28+1,5) / 1,2=7,32$} \\
\hline TRIX (DIN,TP) & \multicolumn{3}{|c|}{$\log \left(\mathrm{Ch}^{*} \mathrm{aD} \% \mathrm{O} * \mathrm{DIN} * \mathrm{TP}\right)=6,95$} & & \multicolumn{3}{|c|}{$(6,95+1,5) / 1,2=7,04$} \\
\hline TRIX (DIN,DIP) & \multicolumn{3}{|c|}{$\log (\mathrm{Ch} * \mathrm{aD} \% \mathrm{O} * \mathrm{DIN} * \mathrm{DIP})=6,51$} & & \multicolumn{3}{|c|}{$(6,51+1,5) / 1,2=6,88$} \\
\hline
\end{tabular}

Di awal pengembangannya, TRIX menggunakan data yang dikumpulkan oleh Oceanographic Division of the Emilia-Romagna Regional Environmental Protection Agency (ARPAE-Daphne) pada kurun waktu antara 1982 hingga 1993. Meskipun demikian, TRIX saat ini telah digunakan secara luas. Tidak hanya di Italia saja, TRIX juga digunakan di negara uni eropa lainnya. Bahkan, TRIX juga digunakan untuk asesmen eutrofikasi di perairan pesisir Brazil (Alves et al., 2013), Turki (Kovalova \& Medinets, 2012) dan Indonesia (Tammi et al., 2015). Akan tetapi, masih ada yang meragukan bahwa indeks ini berlaku umum untuk semua perairan pesisir khususnya perairan yang termasuk kategori oligotrofi (Primpas \& Karydis, 2011). Untuk itu, mereka merekomendasikan skala yang baru untuk membedakan karakteristik perairan berdasarkan produktivitasnya (Tabel 4). Di pihak lain, Karbassi et al. (2016) menggunakan konstanta yang berbeda dalam perhitungan indeks TRIX. Untuk mengetahui kualitas air Laut Oman, konstanta $-1,5$ dan 1,2 pada persamaan 1 yang diusulkan oleh Vollenweider et al. (1998) berturut turut diganti dengan $-1,1$ dan 0,84 . 
Tabel 4. Perbandingan skala TRIX awal (Vollenweider et al., 1998) dengan skala TRIX baru yang diusulkan oleh Primpas \& Karydis (2011).

\begin{tabular}{|c|c|c|}
\hline Tipe perairan & Skala TRIX awal & Skala TRIX baru \\
\hline Ultra oligotrofi & & $0-1,6$ \\
\hline Oligotrofi & $0-4$ & $1,6-2,8$ \\
\hline Mesotrofi & $4-5$ & $2,8-4,0$ \\
\hline Eutrofi & $5-6$ & $4,0-5,3$ \\
\hline Hipertrofi & $6-10$ & \\
\hline Distrofi & & $5,3-10,0$ \\
\hline
\end{tabular}

\section{PENUTUP}

Seiring dengan semakin meningkatnya intensitas eutrofikasi di perairan pesisir, maka diperlukan suatu usaha untuk memonitor kualitas air lingkungan pesisir dan laut sebagai upaya mengurangi resiko kerusakan lingkungan yang diakibatkan oleh eutrofikasi. Saat ini telah banyak metode yang dikembangkan sebagai instrumen untuk mengkaji produktivitas perairan pesisir dan juga tingkat eutrofikasinya. Salah satu yang umum digunakan adalah indeks eutrofikasi atau TRIX. Metode ini banyak digunakan karena dianggap lebih efektif dibandingkan dengan metode lainnya. Namun demikian, metode ini masih perlu untuk dievaluasi kembali apakah indeks yang digunakan berlaku secara universal ataukah perlu adanya penyesuaian skala pada indeks tersebut untuk diterapkan pada wilayah perairan yang berbeda.

\section{DAFTAR PUSTAKA}

Alves, G., M. Flores-Montes, F. Gaspar, J. Gomes and F. Feitosa. 2013. Eutrophication and water quality in a tropical Brazilian estuary. Journal of Coastal Research special issue(65): 7-12.

Boesch, D. F. 2002. Challenges and opportunities for science in reducing nutrient over-enrichment of coastal ecosystems. Estuaries 25: 744-758.

Costanza, R. 1992. Towards an operational definition of health. In: R. Costanza, B. Norton and B. D. Haskell (Eds.).Ecosystem health $=$ New goals for environmental management. Island Press, Washington, D.C.: 239-256.

Dodds, W. K. 2006. Nutrients and the "dead zone": the link between nutrient ratios and dissolved oxygen in the northern Gulf of Mexico. Frontiers in Ecology and the Environment 4(4): 211-217.

Ferreira, J. G., J. H. Andersen, A. Borja, S. B. Bricker, J. Camp, M. Cardoso da Silva, E. Garcés, A-S. Heiskanen, C. Humborg, L. Ignatiades, C. Lancelot, A. Menesguen, P. Tett, N. Hoepffner and U.Clauss- 
en. 2010. Marine Strategy

Framework Directive - Task

Group 5 Report Eutrophica-

tion. EUR 24338 EN-Joint

Research Centre, Office for

Official Publications of the European Communities, Luxembourg: 49p.

Ferreira, J. G., J. H. Andersen, A. Borja, S. B. Bricker, J. Camp, M. Cardoso da Silva, E. Garcés, A-S. Heiskanen, C. Humborg, L. Ignatiades, C. Lancelot, A. Menesguen, P. Tett, N. Hoepffner and U. Claussen. 2011. Overview of eutrophication indicators to assess environmental status within the European Marine Strategy Framework Directive. Estuarine, Coastal and Shelf Science 93: 117-131.

Fiori, E., M. Zavatarelli, N. Pinardi, C. Mazziotti and C. R. Ferrari. 2016. Observed and simulated trophic index (TRIX) values for the Adriatic Sea basin. Natural Hazards and Earth System Sciences 16: 2043-2054.

Giovanardi, F. and A. Vollenweider. 2004. Trophic conditions of marine coastal waters: experience in applying the trophic index TRIX to two areas of the Adriatic and Tyrrhenian Seas. Journal of Limnology 63(2): 199-218.
Gray, J.S. 1992. Eutrophication in the sea. In: G. Colombo, I. Ferrari, V. U. Ceccherelli and R. Rossi (eds.). Marine eutrophication and population dynamics. Olsen \& Olsen, Fredensborg: 3-16.

Ibrahim, A. M. M. 2007. Review of the impact of harmful algae blooms and toxins on the world economy and human health. Egyptian Journal of Aquatic Research 33(1): 210-223.

Karbassi, A. R., E. M. Abdollazadeh, G. Attaran-Fariman, M. Nazariha and M. Mazaheri-Assadi. 2016. Development of trophy index along South-East Coast of Oman Sea and its relationship with harmful algae bloom. Journal of Applied Environmental and Biological Sciences 6(10): 19-27.

Karydis, M. 2009. Eutrophication assessment of coastal waters based on indicators: a literature review. Global NEST Journal 11(4): 373-390.

Kovalova, N and V. Medinets. 2012. Comprehensive assessment of long-term changes of the Black Sea surface waters quality in the Zmiinyi Island area. Turkish Journal of Fisheries and Aquatic Sciences 12: 485-491. 
Lapointe, B. E., D. A. Tomasko and W. R. Matzie. 1994. Eutrophication and trophic state classification of seagrass communities in the Florida Keys. Bulletin of Marine Science 54(3): 696-717.

Moncheva, S., V. Dontcheva, G. Shtereva, L. Kamburska, A. Malej and S. Gorinstein. 2002. Application of eutrophication indices for assessment of the Bulgarian Black Sea coastal ecosystem ecological quality. Water Science and Technology 46(8): 19-28.

Nixon, S.W. 1995. Coastal marine eutrophication: a definition, social causes and future concerns. Ophelia 41: 199-219.

Primpas, I. and M. Karydis, 2011. Scaling the rophic index (TRIX) in oligotrophic marine environments. Environmental Monitoring and Assessment 178: 257-269.

Snickars, M., B. Weigel and E. Bonsdorff. 2015. Impact of eutrophication and climate change on fish and zoobenthos in coastal waters of the Baltic Sea. Marine Biology 162: 141-151.
Tammi, T., N. T. M. Pratiwi, S. Hariyadi and I. N. Radiarta. 2015. Aplikasi analisis klaster dan indeks TRIX untuk mengkaji variabilitas status trofik di Teluk Pegametan, Singaraja, Bali. Jurnal Riset Akuakultur 10(2): 271-281.

Vollenweider, R. A., F. Giovanardi, G. Montanari and A. Rinaldi. 1998. Characterization of the trophic conditions of marine coastal waters with special reference to the NW Adriatic Sea: proposal for a trophic scale, turbidity and generalized water quality index. Envirometrics 9: 329357.

Vollenweider, R.A. 1992. Coastal marine eutrophication: principles and control. In: R. A. Vollenweider, R. Marchetti and R. Viviani (eds.). Marine Coastal Eutrophication. Elsevier, London: 1-20. 